\title{
O edema de mama em bovinos leiteiros
}

\section{Udder edema in dairy cattle}

\author{
Wilmar Sachetin Marçal ${ }^{1}$
}

\section{Resumo}

Este trabalho tem por objetivo apresentar uma revisão sobre o Edema de Mama, destacando formas clínicas de manifestações e as principais etiologias até então reconhecidas por pesquisadores. Mereceu destaque também, a descrição de medidas terapêuticas e profiláticas, incluindo condutas de manejo de novilhas e vacas susceptíveis, visando minimizar o problema e prevenir outras enfermidades que a glândula mamária possa adquirir.

Palavras-chave: Edema de mama, etiologia, tratamento, profilaxia, revisão

\begin{abstract}
A review about Udder Edema is presented. The author describes the clinical forms and the most important etiologies recognized until now. Therapeutic and prophylatic conducts also are emphasized, including resolutions of management for heifers and cows to prevent other diseases of udder.
\end{abstract}

Key words: Udder edema, etiology, treatment, prophylaxis, review

\section{Introdução}

À medida que os produtores rurais buscam aumentar a produção animal num curto espaço de tempo, alguns distúrbios fisiológicos e metabólicos surgem com mais evidência nos rebanhos, especialmente nos bovinos leiteiros. Neste particular, destaca-se a entidade clínica conhecida por Edema de Mama ou Edema de Úbere, que, dependendo da evolução, pode causar danos à saúde do animal e prejuízos econômicos aos criadores. A ocorrência do Edema de Mama é variável entre rebanhos. No Canadá, um estudo envolvendo 12.000 vacas em 434 rebanhos, revelou a incidência de $18 \%$ desse distúrbio (SNIDER; BRIGHTENBACK; SIEGMUND,
1962). Entretanto, Hayes e Albright (1976) nos Estados Unidos, detectaram, num determinado lote de animais, que $96,4 \%$ dos bovinos demonstraram Edema de Mama durante o primeiro parto. Embora as estatísticas em muitos outros países, inclusive no Brasil, não sejam conhecidas, sabe-se que, no aprimoramento de produtividade nas vacas leiteiras, o Edema de Mama pode surgir com mais evidência nos rebanhos (MARÇAL; VAN WESTERING, 2002).

O Edema de Mama é um problema clínico que ocorre num momento crítico do ciclo da lactação, pouco antes e/ou depois do parto, no período periparto

\footnotetext{
1 Médico veterinário, Professor Associado do Departamento de Clínicas Veterinárias, Centro de Ciências Agrárias, Universidade Estadual de Londrina. E-mail: wilmar@uel.br

* Autor para correspondência.
} 
(THAKUR; SUDHAN; AZMI, 1989). É mais comum em novilhas do que em animais adultos (GILBERT; SCHWARK, 1992). Em muitos casos clínicos, o inchaço do úbere diminui gradualmente com a ordenha. Porém, em alguns bovinos esse distúrbio pode se tornar severo, causando dor e desconforto ao animal acometido e, quando isso ocorre, é necessária uma intervenção clínica imediata (MARÇAL, 1991). Nos casos em que a severidade não é atenuada, outros problemas podem advir, incluindo mastite (VANDORP et al., 1999; WAAGE et al., 2001). O manejo na linha de ordenha se altera, porque a colocação das teteiras da ordenhadeira mecânica torna-se mais difícil e demorada. O mais grave, entretanto, é que o Edema de Mama torna a fêmea bovina mais vulnerável a traumas, injúrias e lesões da própria glândula mamária e estruturas adjacentes, podendo acarretar deterioração permanente dos ligamentos suspensores e tecidos do úbere (VESTWEBER; AL-ANI, 1983), raramente evoluindo para agalaxia (PRABHAKAR et al., 1991). Pode ocorrer ainda desde uma simples dermatite que, em casos graves, pode evoluir para necrose local da pele lembrando gangrena, exalando mau cheiro (GILBERT; SCHWARK, 1992), condenando o animal sob o ponto de vista comercial e econômico (MARÇAL; VAN WESTERING, 2001).

Isso posto, o presente trabalho tem por objetivo apresentar uma abordagem revisional sobre o edema de mama, considerando as formas clínicas de manifestações e aspectos etiológicos. Merecerá destaque, também, a descrição de medidas terapêuticas e profiláticas, incluindo aspectos do manejo de novilhas e vacas, visando minimizar o distúrbio e prevenir enfermidades e/ou injúrias que a glândula mamária possa sofrer.

\section{Revisão da literatura}

a) Conceito da doença

Entende-se por edema ou congestão da mama como sendo um distúrbio da glândula mamária, caracterizado por um acúmulo excessivo de fluído nos espaços teciduais intercelulares (MORROW; SCHMIDT, 1964; VESTWEBER; AL-ANI, 1983). A intensidade de manifestação clínica em bovinos leiteiros tem sido classificada ou sub-dividida na forma de escore. Segundo Carlsen, Keith e Croshae (1969) e Hemken, Choate e Plowman (1969) esse escore é classificado da seguinte maneira: $1=$ sem edema; 2 = com edema leve; 3 = com edema moderado; 4 = com edema severo e 5 = edema muito severo. $\mathrm{O}$ escore era classificado por Dentine e McDaniel (1984) incluindo a mensuração do comprimento, altura e largura do úbere acometido (volume), além da inspeção visual, possibilitando melhor noção do prognóstico (VESTWEBER; AL-ANI, 1983). Por outro lado, Tucker et al. (1992) apresentaram uma sistemática diferente de escore do edema de mama, com uma amplitude maior, ou seja, de 0 (nenhum edema) a 10 (edema severo). No estudo epidemiológico, que realizaram em 108 bovinos, de representativas bacias leiteiras no Brasil, Marçal e van Westering (2002) encontraram 23 animais $(21,29 \%)$ com escore 2 , tendo o mais novo 24 meses de idade e o mais velho 195 meses; 57 animais $(52,78 \%)$ com escore 3 , sendo o mais velho com 105 meses e o mais novo com 21 meses de vida; e 28 bovinos $(25,93 \%)$ apresentaram escore 4 , com 28 meses para o mais novo e 175 meses de idade para o mais velho.

\section{b) Formas clínicas}

Segundo Morrow e Schmidt (1964), duas formas de edema de mama são conhecidas. A primeira chamada de aguda ou fisiológica ocorre próxima ao parto e pode abranger duas a três semanas antes do parto, estendendo-se até o momento da parturição, podendo persistir por duas a três semanas pós-parto. Esta condição é comumente observada em novilhas de primeira cria de alta produção (SETTI; SCHALCH; ZANETTI, 1998; STALLINGS, 2000), mas também em vacas com sucessivas parturições (VESTWEBER; AL-ANI, 1983). O edema de mama é simétrico sobre a totalidade da glândula mamária e 
pode se estender para áreas adjacentes do abdômen e períneo (SWETT; MATTHEWS; GRAVES, 1938), passando pela veia mamária (veia do leite), que se mostra extremamente ingurgitada. Em alguns casos, a inflamação pode abranger da vulva até a região do esterno. Nos animais acometidos, a pele torna-se tensa sobre as partes intumescidas do úbere, manifestando "Sinal de Godet positivo", ou ainda "Sinal de Cacifo positivo" (MARÇAL, 1991; MARÇAL; VAN WESTERING, 2001). Algumas novilhas, conforme destaca Rebhun (1995), demonstram abdução de membros posteriores, compensando a dor e o desconforto pelo inchaço do úbere. Pela expansão provocada na glândula mamária, a locomoção do animal e o ato de deitar-se ficam dificultados (MARÇAL, 1991; MARÇAL; VAN WESTERING, 2001).

Conforme destacam Hicks e Pauli (1976) e Sanders e Sanders (1981), o segundo tipo de edema de mama é classificado como sendo uma forma crônica, ocorrendo normalmente como seqüela da forma aguda. Esta condição segundo Rice e Grant (1996), pode ser devida, também, a hipomagnesemia e anemia, muito embora sejam situações pouco incomuns em vacas leiteiras estabuladas. A forma crônica pode persistir por diversos meses após o parto, desaparecendo durante a metade da fase de lactação e voltando a mostrar-se meses antes da próxima lactação (AMSTUTZ, 1982; JONES; KINIGHT; EVANS, 1984). A intumescência é mais evidente na parte ventral-posterior e pode envolver um ou dois quartos mamários (VESTWEBER; ALANI, 1983). Nesta fase, devido a cronicidade do problema, pode haver esclerodermia da face lateral do úbere (BLOOD; HENDERSON; RADOSTITS, 1983), a mama torna-se maior, mais firme à palpação e mais pendulosa a cada parto. O sistema suspensório pode manifestar comprometimento com divergências dos tetos, por causa do relaxamento do ligamento suspensório medial (VESTWEBER; AL-ANI, 1983), caracterizando perda zootécnica da vaca acometida (MARÇAL; VAN WESTERING, 2001).
Nos 108 bovinos leiteiros observados por Marçal e van Westering (2002), não foram detectados casos crônicos de manifestação do Edema de Mama. Os autores encontraram 58,33\% dos casos com manifestação mais evidente nas duas semanas pósparto, seguida de $39,81 \%$ dos casos com mais representatividade de sinais nas duas semanas que antecediam o parto. Em 1,86\% dos animais não houve diferença acentuada, sendo observado evidência de sinais tanto antes como depois do parto, porém todos na fase aguda de manifestação.

\section{c) Causas do Edema de Mama}

Schultz (1978) afirma que o problema é multifatorial, no entanto Sanders e Sanders (1981) não reconhecem ainda uma causa precisa para o edema de mama. Os fatores incriminados e envolvidos, até então, são os seguintes:

$\left.1^{\circ}\right)$ Fatores ligados a herdabilidade:

A severidade do edema de mama é baseada num fenômeno fisiológico, pois algumas vacas tendem a mostrar o mesmo problema ano após ano (MARÇAL; VAN WESTERING, 2002). Um estudo com investigação genética sugeriu que há uma alta, significante e positiva correlação entre produção leiteira e edema de mama, havendo herdabilidade maior para a produção leiteira. Por essa razão, segundo Norman e van Vleck (1972) e Nestor (1998) acredita-se ser um fator indireto, ocorrendo como uma conseqüência de alterações fisiológicas em bovinos de alta produção leiteira (MARÇAL; VAN WESTERING, 2001). Embora não detalhe dados experimentais, Nestor (1998) afirma que algumas vacas parecem ser geneticamente mais propensas ao Edema de Mama.

\section{$\left.2^{\circ}\right)$ Distúrbios circulatórios:}

Estase de sangue venoso ou do fluxo linfático durante a gestação, devido à pressão do feto na 
cavidade pélvica são considerados como causa primária do edema de mama (AHMAD, 1978; CARROLL, 1981; MARÇAL; VAN WESTERING, 2002). O aumento no fluxo sangüíneo para o úbere e um decréscimo associado na quantidade de sangue que sai do úbere, resultando em uma alta pressão hidrostática capilar e conseqüente edema, também é incriminado como uma causa do distúrbio (HEIDRICH; RENK, 1967; VESTWEBER; ALANI, 1985). Este aspecto pode ser considerado previsível, pois para se produzir um litro de leite, circulam aproximadamente 400 litros de sangue pelo úbere (VESTWEBER; AL-ANI, 1983), algo em torno de $280 \mathrm{ml}$ por segundo (HURLEY, 2000). De acordo com Vestweber e Al-Ani (1985), as vacas com edema do úbere apresentam uma diminuição significativa do fluxo mamário sangüíneo associado a um aumento da pressão venosa da veia epigástrica superficial cranial, havendo uma correlação negativa entre o fluxo mamário sangüíneo e a pressão sangüínea da veia epigástrica superficial cranial no parto. O aumento na formação de linfa, devido a um aumento do metabolismo tecidual, pode resultar em uma inabilidade dos vasos linfáticos em remover toda a linfa e causar o problema (MORROW; SCHMIDT, 1964). A estase de leite no úbere, comumente observada em novilhas, devido a aspectos de deficiência na descida do leite, é considerada outra causa do edema de mama (GOUGE; SHOR; JOHNSON, 1959). Segundo Rebhun (1995) a hipoproteinemia, em especial baixos níveis de albumina, em vacas afetadas pelo distúrbio, podem contribuir para o agravamento do quadro.

$3^{\circ}$ ) Fatores relacionados à dieta:

A alimentação com excesso de suplementos energético-concentrados, como grãos (SCHMIDT; SCHULTZ, 1959; HEMKEN; GAINER, 1960), ainda continuam sendo apontadas como importantes fatores na manifestação e na exacerbação do problema (MARÇAL; VAN WESTERING, 2001; MARÇAL; VAN WESTERING, 2002). Segundo
Rice e Grant (1996) a oferta exagerada de proteína para vacas susceptíveis também pode aumentar a predisposição na manifestação do edema de mama, apesar de ser situação incomum, pois as dietas são sempre balanceadas e o excesso de proteína na alimentação não é comum de acontecer (MARÇAL; VAN WESTERING, 2002).

Um estudo realizado em vacas e novilhas da raça holandesa preta e branca revelou que uma dieta a base de grãos, 21 dias antes do parto, exacerbou a severidade do edema de mama nas novilhas, por aumentar a pressão intramamária, impedindo a drenagem linfática e venosa (EMERY; HAFS; ARMSTRONG, 1969).

Hutjens (1980) efetuou um estudo com 3 diferentes tipos de ração, 30 dias antes do parto em vacas sadias de alta produção, observando que, no lote que recebeu ração rica em grãos e silagem, evidenciou-se mais edema de mama e posteriormente mastite. Ainda na questão alimentar, Vigue (1963) já havia detectado que vacas obesas podem ser mais susceptíveis ao edema de mama, bem como a cetose ou acetonemia.

Estudos têm demonstrado haver uma relação entre edema de mama e a ingestão de cloreto de sódio pela dieta (RANDALL et al., 1974; SANDERS; SANDERS, 1981), ou pela água de bebida dos bovinos (McBRIDE, 1997). A alimentação com excesso de potássio pode ser também uma causa do Edema de Mama (SANDERS; SANDERS, 1982). Esse excesso de potássio, conforme Vestweber e Al-Ani (1983), pode advir da própria alimentação com grãos ou pela adição de potássio na forma de fertilizantes ao solo, para melhorar a produção da matéria vegetal, como por exemplo, na silagem de milho ou na alfafa.

\section{$\left.4^{\circ}\right)$ Outros fatores implicados:}

Segundo Hayes e Albright (1976) o edema de mama mostra uma tendência de se manifestar menos severo conforme os animais envelhecem. O trabalho 
demonstrou que a incidência do distúrbio em animais da raça holandesa preta e branca, durante a primeira lactação foi $37,5 \% ; 19,4 \%$ na segunda lactação; $16,7 \%$ na terceira; $18,7 \%$ na quarta lactação e $6,9 \%$ na quinta ou mais lactações. Os autores observaram, também, que se as novilhas estivessem mais velhas no primeiro parto, o problema com edema de mama parecia ser mais evidente. Assim sendo, dos animais que pariram entre 23 a 26 meses de idade, $17,6 \%$ tiveram edema severo; com 27 a 28 meses $44,4 \%$ tiveram edema severo e, entre 29 a 37 meses $56 \%$ tiveram edema severo. No mesmo estudo, ainda, foi observado que nos bovinos com período seco muito longo, havia uma maior incidência do edema de mama. Vacas secas com menos de 50 dias, 5,1\% tiveram edema severo; entre 51 e 70 dias, 13,5\% tiveram edema severo; $10,3 \%$ tiveram edema quando o período seco foi entre 71 e 90 dias e, $28,3 \%$ mostraram edema severo, cujo período seco era maior que 90 dias.

Em outros ensaios, na busca de outras possíveis causas ficou comprovado por Larson, Rolleri e Kendall. (1954) que, durante estágios diferentes da gestação e lactação em bovinos acometidos pelo distúrbio, os níveis totais de proteína sérica estavam menores no dia do parto, retornando ao normal bem rapidamente logo após a parturição. O decréscimo nos níveis de proteínas séricas pode ser devido a perdas de imunoglobulinas, especialmente de globulinas d 1 e b 2, além de a globulinas do sangue para o colostro. Acredita-se que isso cause uma diminuição na pressão oncótica plasmática do sistema vascular, resultando no desenvolvimento do edema de mama em algumas fêmeas (LARSON; KENDALL, 1957).

Fatores hormonais endógenos parecem contribuir para o desenvolvimento do edema de mama. Conforme destacam Malven et al. (1983), em novilhas da raça holandesa preta e branca, o Estradiol 17 a e a Estrona promoveram e/ou aumentaram a severidade do edema de mama antes do parto, ao passo que a progesterona e o estradiol $17 \mathrm{~b}$ desfavoreceu-o no pré-parto. Ainda segundo os autores, o estradiol $17 \mathrm{~b}$ evitou o favorecimento da manifestação do edema de mama em vacas, logo após o parto.

Vanderkolk, Wensing e Breukink. (1991) descreveram o possível envolvimento do eixo adrenocortical-pituitária no edema de mama. A pesquisa foi conduzida em 60 vacas da raça holandesa preta e branca e vermelha e branca, cuja prevalência do distúrbio era de $75 \%$ no rebanho. Os autores demonstraram a associação do edema de mama com insuficiência adrenocortical em uma vaca do lote examinado.

Conforme Rebhun (1995) a metrite pós-parto tem sido associada com a persistência do edema de mama, muito embora ainda não se conheça plenamente a patofisiologia desta relação. Nestor (1998) ainda cita como causas do edema de mama algumas micotoxinas, tais como a Zearalenona, causando inchaço edematoso no úbere, além do uso de somatotropina que, segundo o autor, aumenta muito o fluxo sangüíneo no úbere e causa o problema, em algumas vacas.

Ao considerar ainda alguns aspectos etiológicos, Hurley (2000) enfatiza que, com base em estudos da Medicina Humana, além da ingestão de cloreto de sódio com acúmulos de fluídos, o desconforto animal por temperaturas ambientais muito elevadas (estresse térmico), e os danos na inervação mamária, podem contribuir para a manifestação dessa entidade em bovinos leiteiros.

\section{d) Considerações terapêuticas e profiláticas}

O primeiro tratamento efetivo descrito na literatura para o edema de mama foi a acetozolamida, um diurético não mercurial (GOUGE; SHOR; JOHSON, 1959). Depois surgiram outras drogas diuréticas (VESTWEBER; AL-ANI, 1983; VESTWEBER; AL-ANI, 1989); injeções de corticóides (JANESKI; CRCEV; PANOSKI, 1988; GILBERT; SCHWARK, 1992); associação injetável de corticóides e 
antibióticos (JANESKI; CRCEV; PANOSKI, 1988) e corticóides associados com diuréticos, ambos injetáveis (CARLSEN; KEITH; CROSHAE, 1969; MITCHELL et al., 1976; VESTWEBER; AL-ANI, 1983; MARÇAL, 1991; MARÇAL; VAN WESTERING, 2002). Alternativas terapêuticas complementares são mencionadas incluindo-se aplicação de linimentos tópicos (FILIPOVIC et al., 1989), além de duchas e massagens, algumas vezes provocando choque térmico local com calor e frio (GILBERT; SCHWARK, 1992). Há descrição também de tratamento cirúrgico de casos não responsivos, com incisão na pele do úbere e da região afetada, sem atingir o tecido secretório mamário, mas necessitando de ininterruptos cuidados de higiene e enfermagem veterinária (AL-ANI; VESTWEBER, 1984).

As medidas profiláticas mais recomendadas são melhorias no manejo das novilhas e vacas de alta produção (WELDY, 1979), tais como: $1^{\text {a }}$ ) nas propriedades leiterias que possuem boa e disponível mão de obra é importante se exercitar os bovinos com caminhadas, antes e depois do parto, em horários de temperatura amena (MARÇAL, 1991), sobre terrenos planos, com baixa velocidade, cerca de 1 a 1,5 km por dia, para bom condicionamento físico, especialmente no pré-parto; $2^{\mathrm{a}}$ ) redução no excesso de grãos no pré-parto, principalmente para novilhas e vacas susceptíveis (VESTWEBER; AL-ANI, 1983); $3^{\text {a }}$ ) controle da dieta catiônica-aniônica no préparto (BLOCK, 1994; SETTI; SCHALCH; ZANETTI, 1998), especialmente em granjas leiteiras com formas endêmicas do edema de mama, conhecendo e controlando níveis de potássio e sódio alimentares (REBHUN, 1995); $4^{\text {a }}$ ) ordenhas freqüentes e controladas no pós-parto, para reduzir a congestão (BLOOD; HENDERSON; RADOSTITS, 1983; MARÇAL, 1991; REBHUN, 1995); $5^{\text {a }}$ ) tratar imediatamente as metrites pós-parto (REBHUN, 1995); 6 ${ }^{\mathrm{a}}$ ) disponibilizar livre acesso à água de bebida para os animais (MARÇAL, 1991; MARÇAL; VAN WESTERING, 2002).

Sobre o uso do cloreto de cálcio, adicionado à ração no pré-parto, como forma de prevenção do edema de mama, a literatura ainda não está bem concisa nesse aspecto. $\mathrm{O}$ produto tem sido utilizado para reduzir a Hipocalcemia da Vaca Leiteira e alguns pesquisadores afirmam que pode haver uma redução na severidade do edema de mama (LEMA et al., 1992). Contrariamente, Miller et al. (1993b) não observaram qualquer melhora em bovinos com Edema de Mama pelo uso do cloreto de cálcio.

Permanecem ainda como meta de mais investigações a suplementação com vitamina E e sais de magnésio no pré-parto, como forma preventiva ao edema de mama em rebanhos susceptíveis. Kelly et al. (1990) ao suplementarem bovinos com uma combinação de ambos os ingredientes, perceberam melhores resultados do que quando se administrouos isoladamente. Em contrapartida, Thomas, Miller e Mueller (1990) observaram resultados mais promissores, somente quando se administrou a vitamina E sozinha, ou seja, sem a combinação com sais de magnésio.

Miller et al. (1993a) objetivando averiguarem radicais livres originados a partir de metabólitos reativos de oxigênio, estudaram os efeitos do chamado "estresse oxidativo" e dos agentes oxidantes sobre o metabolismo e a saúde animal. Segundo os autores, havia evidências que o "estresse oxidativo" pudesse contribuir com a manifestação de edema de mama e alteração do desempenho reprodutiva em bovinos da raça holandesa preta e branca. No experimento ficou comprovado que o "estresse oxidativo" na vaca leiteira periparturiente, contribuiu para o desenvolvimento do edema de mama, hipocalcemia, retenção de placenta, mastite e diminuição na performance reprodutiva dos animais. Em virtude disso, os autores destacam a necessidade de se suplementar os bovinos leiteiros com agentes antioxidantes, tais como vitamina E, bcaroteno, glutation, urato, entre outros.

Ainda sobre esse aspecto, Mueller et al. (2002) enfatizaram que o edema de mama pode ser proveniente do "estresse oxidativo", porque os metabólitos reativos de oxigênio não são bem 
controlados ou metabolizados pelo organismo. Segundo os autores, a predisposição ao edema de mama ocorre após alterações na membrana celular por agentes oxidantes, bem como as ações causadas por enzimas esteroidogênicas específicas, levando a alteração na síntese hormonal. Conforme ainda destacam, a suplementação com agentes antioxidantes é benéfica para o organismo de vacas leiterias susceptíveis, podendo-se utilizar as vitaminas E, A ou C, bem como o b-caroteno e o glutation. Ainda, segundo os autores, muitos outros agentes antioxidantes são produzidos endogenicamente pelos animais; porém para a sua perfeita ação contra radicais livres é preciso que haja boa suplementação com proteína, energia e os elementos minerais cobre, zinco, selênio e magnésio. Por fim, os estudiosos recomendam não abusar da suplementação com ferro e molibdênio, pois embora também sejam antioxidantes, quando administrados em excesso passam a ser perigosos ao organismo animal.

\section{Conclusões}

Do ponto de vista etiológico, pela literatura compulsada, a causa precisa do edema de mama ainda continua sendo investigada, sendo provável que o distúrbio seja mesmo uma manifestação decorrente de multifatores. A forma aguda, ou seja, com manifestação no periparto, ainda continua sendo a mais observada e a mais citada, sendo raros os relatos de forma crônica de manifestação.

Não se verificou qualquer droga nova que merecesse destaque terapêutico na presente revisão. Existem sim nutrientes que, incluídos na dieta dos animais, exercem efeitos preventivos. Por essa e por outras razões é que as medidas profiláticas continuam sendo importantes para animais propensos à manifestação do edema de mama. Nesse aspecto, destaca-se exercícios e um ininterrupto monitoramento dos animais, principalmente para se evitarem injúrias à mama e infecções como Mastite.
Permanecem ainda sem uma definitiva explicação a questão do desconforto animal por "estresse térmico" e a incidência do edema de mama, embora a citação encontrada refere-se a ensaios em seres humanos. É provável que haja correlação. Dietas com manipulação de cátions-ânions parecem ainda incipientes na interelação com o distúrbio. A literatura referencia mais o balanço daquelas dietas como preventivo a Hipocalcemia da Vaca Leiteira, distúrbio metabólico esse que tem sido também a principal razão da utilização do cloreto de cálcio nas rações.

Os fatores hormonais endógenos influenciando na manifestação do edema de mama, bem como novos ensaios sobre micotoxinas interagindo no desencadeamento do distúrbio, poderiam ser objetos de mais ensaios e pesquisas. Além disso, o uso da somatotropina deveria ser igualmente avaliado, para se conhecer outras ações desse produto, além do aumento no fluxo de sangue para o úbere. Obesidade poderia também ser um tema mais estudado, visando verificar o grau de correlação entre a condição corporal e o edema de mama. A propósito dos agentes antioxidantes, sem dúvida alguma, este parecer ser um campo muito fértil e promissor, podendo nortear novas pesquisas, visando elucidar, ainda mais, as razões que possam explicar a etiologia deste distúrbio e como preveni-los.

\section{Referências}

AHMAD, I. Physiological udder edema and congestion of cows and buffaloes. Pakistan Journal of Health., Lahore, v.31, p.13-15, 1978.

AL-ANI, F. K.; VESTWEBER, J. G. E. Mamary blood-flow measurements associated with the development of bovine udder edema. American Journal of Veterinary Research, Chicago, v.45, n.2, p.339-341, 1984.

AMSTUTZ, H. E. Chronic udder edema in a holstein herd. Modern Veterinary Practice, Santa Barbara, v.63, n.1, p.53$55,1982$.

BLOCK, E. Manipulation of dietary cation-anion difference on nutritionally related production diseases, productivity and metabolic responses of dairy cows. Journal of Dairy Science, Champaign, v.77, n.5, p.1437-1450, 1994. 
BLOOD, D. C.; HENDERSON, J. A.; RADOSTITS, O. M. Clínica Veterinária. 5.ed. Rio de Janeiro: Guanabara Koogan, 1983.

CARLSEN, H. E.; KEITH, J. M.; CROSHAE, J. E. Effect of trichlormethiazide and dexametasone on control of udder edema and milk production in lactating dairy cows. Journal of Dairy Science, Champaign, v.52, n.2, p.281, 1969.

CARROLL, E. J. Physiopathology of the mammary system. In: HOWARD, J. H. (Ed.). Current veterinary therapyfood animal practice. Philadelphia: Saunders, 1981. p.942.

DENTINE, M. R.; MCDANIEL, B. T. Associations of subjective udder edema scores and descriptive trait codes for udder types. Journal of Dairy Science, Champaign, v.67, n.1, p.208-215, 1984.

EMERY, R. S.; HAFS, H. D.; ARMSTRONG, D. Prepartum grain feeding effects on milk production, mammary edema, and incidence of diseases. Journal of Dairy Science, Champaign, v.52, n.3, p.345-351, 1969.

FILIPOVIC, P. M.; HAYDAREVIC, F.; MAGLAJLIJA, A; KLANCEVIC, J.; LOKVANCIC, H.; PODZO, M; LUBOVAC, A. Prilog terapiji i saniranju edema vimena kod domacih zivotinja. Veterinaria (Sarajevo), Sarajevo, v.38, n.3-4, p.433-437, 1989.

GILBERT, R. O.; SCHWARK, W. S. Udder edema. The Veterinary Clinics of North America, Philadelphia, v.8, n.1, p.35-37, 1992.

GOUGE, H. E.; SHOR, A. L.; JOHNSON, W. P. Control of udder edema in dairy cows. Veterinary Medicine, Bonner Springs, v.54, p.343-345, 1959.

HAYES, R. L.; ALBRIGHT, J. L. Older heifers have more severe edema. Hoard's Dairyman, Fort Atkinson, v.2, p.75, 1976.

HEIDRICH, H. J.; RENK, W. (ed.) Disturbances of circulation. In: . Diseases of the mammary glands of domestic animals. Philadelphia: Saunders, 1967. p.99-112.

HEMKEN, R. W.; CHOATE, W. H.; PLOWMAN, R. D. Salt and water intake as related to udder edema. Journal of Animal Science, Savoy, v.28, n.6, p.874, 1969.

HEMKEN, R. W.; GAINER, E.; DAVIS, R. F. Effect of kind and level of concentrates on udder edema Journal of Animal Science, Savoy, v.43, n.6, p.887-888, 1960.

HICKS, J. D.; PAULI, J. V. Chronic udder edema: clinical aspects of the syndrome and its connection with hypomagnesaemia and anemia. New Zealand Veterinary Journal, Wellington, v.24, p.225-228, 1976.

HURLEY, W. L. Mamary gland anatomy of cattle. Disponível em: <http://classes.aces.uiuc.edu/AnSci308/ anatomyc $>$. Acesso em: 7 set. 2000.
HUTJENS, M. F. Can we feed to prevent udder edema. Hoard's Dairyman, Fort Atkinson, v.178, p.1179, 1980.

JANESKI, K.; CRCEV, D.; PANOSKI, S. Prilog terapiji edema vimena krava i ovaca (treatment of edema of the udder in cows and sheep). Veterinarski Glasnik, Belgrade, v.42, n.8, p.509-514, 1988.

JONES, T. O.; KNIGHT, R.; EVANS, R. K. Chronic udder edema in milking cows and heifers. Veterinary Record, London, v.115, n.9, p.218-219, 1984.

KELLY, F. M.; BERNARD, J. K.; MILLER, J. K.; KI;;ER. F. K.; THOMAS, D. G. Influence of vitamin $\mathrm{E}$ and magnesium supplementation on udder edema in primigravid Holstein heifers. Journal of Dairy Science, Champaign, v.73, n.1, p.166-167, 1990.

LARSON, B. L.; ROLLERI, G. D.; KENDALL, K. A. Changes in bovine blood proteins associated with parturition. Journal of Dairy Science, Champaign, v.37, p.622, 1954.

LARSON, B. L.; KENDALL, K. A. Changes in specific blood serum protein levels associated with parturition in the bovine. Journal of Dairy Science, Champaign, v.40, p.659-666, 1957.

LEMA, M.; TUCKER, W. B.; ASLAM, M.; SHIN, I. S.; LERUYET, P.; ADAMS, G. D. Influence of calcium chloride fed prepartum an severity of edema and lactational performance of dairy heifers. Journal of Dairy Science, Champaign, v.75, n.9, p.2388-2393, 1992.

MALVEN, P. V.; ERB, R. E.; FRANCES D’AMICO, M.; STEWART, T. S; CHEW, B. P. Factors associated with edema of the mammary gland in primigravid dairy heifers. Journal of Dairy Science, Champaign, v.66, n.2, p.246$252,1983$.

MARÇAL, W. S. Pesquisadores desconhecem as causas do edema de mama nas raças leiteiras. O Estado de São Paulo, São Paulo, 22 abr. 1991. Suplemento Agrícola, n 21.

MARÇAL, W.; VAN WESTERING, A. J. Estudo clínico do edema de mama em bovinos leiteiros criados no estado do Paraná. In: CONGRESSO BRASILEIRO DE MEDICINA VETERINARIA, 28., 2001, Salvador. Anais... Salvador: Sociedade Brasileira de Medicina Veterinária, 2001.p.114

MARÇAL, W.; VAN WESTERING, A. J. Aspectos clínicos, epidemiológicos e terapêuticos do edema de mama em bovinos leiteiros. Revista Brasileira de Medicina Veterinária, Rio de Janeiro, v.24, n.3, p.114-117, maio/jun. 2002.

McBRIDE, G. Udder edema. 1997. Disponível em: < http:// www.gov.on.ca/OMAFRA/english/livestock/dairy/forum/ message $>$. Acesso em: 7 set. 2000.

MILLER, J. K.; BRZEZINSKA-SLEBODZINSKA, E.; MADSEN, F. C. Oxidative stress, antioxidants, and animal function. Journal of Dairy Science, Champaign, v.76, n.9, p.2812-2823, 1993a. 
MILLER, T. P.; TUCKER, W. B.; HOGUE, J. F.; SHIN, I.S.; ADAMS, G.D. Effects of calcium chloride on prepartum udder edema and plasma and urine electrolytes in Holstein heifers. Animal Science Research Report, Stillwater, n.933, p.167-174, 1993b.

MITCHELL, R. G.; MATHER, R. E.; SWALLOW, W. H.; RANDY, H. A. Effects of a corticosteroid and diuretic agent on udder edema and milk-yield in dairy-cows. Journal of Dairy Science, Champaign, v.59, n.1, p.109-112, 1976.

MORROW, D. A.; SCHMIDT, G. H. Udder edema. Summit: CIBA Pharmaceutical, 1964.

MUELLER, F. J.; MILLER, J. K.; CAMPBELL, M. H.; MADSEN, F. C. Prevention of udder edema in dairy cows. Disponível em: <http://www.biovance.com/research/ prevention.html>. Acesso em: 11 fev. 2002.

NESTOR, K. E. Udder edema. Jun.1998. Disponível em: $<$ http://www.moormans.com/feedfacts/dairy/dairyjun98/ edema.htm>. Acesso em: 11 fev. 2002.

NORMAN, H. D.; VAN VLECK, L. D. Variation in type traits due to herd, season, and year. Journal of Dairy Science, Champaign, v.55, p.1717-1725, 1972.

PRABHAKAR, S. K; SINGH K. B; SINGH R. P.; KEHRA, S. S; BANSAL, B. K. An unusual case of udder edema leading to agalactia. Indian Veterinary Journal, Madras, v.68, n.6, p.577-578, 1991.

RANDALL, W. E.; HEMKEN, R. W.; BULL, L.; DOUGLAS, L. W. Effect of dietary sodium and potassium on udder edema in holstein heifers. Journal of Dairy Science, Champaign, v.57, n.4, p.472-475, 1974.

REBHUN, W. C. Diseases of cattle. Philadelphia: Lea \& Febiger, 1995.

RICE, D. N.; GRANT, R. Dairy cow health and metabolic disease relative to nutritional factors. 1996. Disponível em: <http://www.ianr.unl.edu/pubs/AnimalDisease/ g1032.htm>. Acesso em: 7 set. 2000.

SANDERS, D. E.; SANDERS, J. A. Chronic udder edema in dairy-cows. Journal of The American Veterinary Medical Association, Schaumburg, v.178, n.12, p.12731274, 1981.

SANDERS, D. E.; SANDERS, J. A. Potassium and udder edema. Journal of The American Veterinary Medical Association, Schaumburg, v.181, n.4, p.324-325, 1982.

SCHMIDT, G. H.; SCHULTZ, L. H. Effect of 3 levels of grain feeding during the dry period on the incidence of ketosis, severity of udder edema, and subsequent milk production of dairy cows. Journal of Dairy Science, Champaign, v.42, n.1, p.170-179, 1959.
SCHULTZ, L. H. Metabolic disorders in dairy cattle. In: WILCOX, C. J.; VAVHORN, H.H., HARRIS, B. (Ed.). Large dairy herd management. Gainesville: University of Florida, 1978. p.393-395.

SETTI, M. C.; SCHALCH, E.; ZANETTI, M. A. Estudo do balanço cation-aniônico da dieta no desempenho de vacas holandesas. Revista Brasileira de Zootecnia, Viçosa, v.27, n.6, p.1241-1247, 1998.

SNIDER, G. W.; BRIGHTENBACK, G. E.; SIEGMUND, O. H. A new approach to edematous conditions of cattle. Canadian Veterinary Journal, Ottawa, v.3, p.150-155, 1962.

STALLINGS, C. Health how to stop udder edema. Disponível em: <http:/www.dairyherd.com/health47.htm>. Acesso em: 7 set. 2000.

SWETT, W. W.; MATTHEWS, C. A.; GRAVES, R. R. Nature of the swelling in the udder of a cow at calving time. Journal of Dairy Science, Champaign, v.21, p.713-714, 1938.

THAKUR, D. K.; SUDHAN, N. A.; AZMI, S. Udder oedema in dairy cows: a clinical study. Indian Veterinary Journal, Madras, v.66, n.5, p.449-450, 1989.

THOMAS, D. G.; MILLER, J. K.; MUELLER, F. J. Udder edema reduced by prepartum, vitamin E supplementation. Journal of Dairy Science, Champaign, v.73, n.1, p.271272, 1990.

TUCKER, W. B.; ADAMS, G. D.; LEMA, M.; ASLAM, M.; SHIN, I. S.; LERUYET, P.; WEEKS, D. L.

Evaluation of a system for rating edema in dairy cattle. Journal of Dairy Science, Champaign, v.75, n.9, p.23822387, 1992.

VANDERKOLK, J. H.; WENSING, T.; BREUKINK, H. J. Udder oedema associated with adrenocortical insuficiency in a herd of Holstein/Friesian cows. Veterinary Record, London, v.128, n.7, p.149-152, 1991.

VANDORP, R. T. E.; MARTIN, S. W.; SHOUKRI, M. M.; NOORDHUIZEN, J. P. T. M; DEKKERS, J. C. M. An epidemiologic study of disease in 32 registered Holstein dairy herds in British Columbia. Canadian Journal of Veterinary Research, Ottawa, v.63, n.3, p.185-192, 1999.

VESTWEBER, J. G. E.; AL-ANI, F. K. Udder edema in cattle. Compendium Continuing Education Practicing Vet., Montreal, v.5, n. 1, p. S5-S12, 1983.

VESTWEBER, J. G. E.; AL-ANI, F. K. Venous blood pressure relative to the development of bovine udder edema. American Journal of Veterinary Research, Chicago, v.46, n.1, p.157-159, 1985. 
VESTWEBER, J. G. E.; AL-ANI, F. K.; JOHNSON, D. E. WAAGE，S.; ODEGAARD， S. A.; LUND，A.; Udder edema in cattle: effects of diuretics (furosemide, BRATTGJERD, S; ROTHE, T. Case control study of risk hydrochlorothiazide, acetazolamide, and 50\% dextrose) on factors for clinical mastitis in postpartum dairy heifers. serum and urine electrolytes American Journal of Journal of Dairy Science, Champaign, v.84, n.2, p.392Veterinary Research, Chicago, v.50, n.8, p.1323-1328, $1989 . \quad 399,2001$.

VIGUE, R.F. Management of udder edema in cattle. WELDY, M. L. How to control mastitis and udder edema. Canadian Veterinary Journal, Ottawa, v.4, p.236-241, Dairy Herd Manage, Minnetonka, v.16, n.6, p.56, 1979. 1963. 